\title{
Clinical Study \\ Comparison of the Neuromuscular Profile of the First Dorsal Interosseous Muscle and the Flexor Hallucis Brevis Muscle as Measured by Electromyography
}

\author{
Yasuyuki Sugi, ${ }^{1}$ Keiichi Nitahara, ${ }^{1}$ Kazuo Higa, ${ }^{1}$ Go Kusumoto, ${ }^{1}$ and Shinjiro Shono ${ }^{2}$ \\ ${ }^{1}$ Department of Anesthesiology, Fukuoka University Faculty of Medicine, Fukuoka 8140180, Japan \\ ${ }^{2}$ Department of Anesthesiology, Fukuoka University Chikushi Hospital, Chikushino 8188502, Japan \\ Correspondence should be addressed to Yasuyuki Sugi, ysugi@fukuoka-u.ac.jp
}

Received 2 November 2011; Accepted 7 December 2011

Academic Editors: D. Karakaya and C. Motamed

Copyright (c) 2011 Yasuyuki Sugi et al. This is an open access article distributed under the Creative Commons Attribution License, which permits unrestricted use, distribution, and reproduction in any medium, provided the original work is properly cited.

Lower limb muscles recover faster than upper limb muscles following administration of nondepolarizing neuromuscular relaxants until the train-of-four ratio (TOFR) reached 0.7. However, no study has been conducted to evaluate the recovery time of the flexor hallucis brevis muscle (FHBM), up to a TOFR of 0.9 , which indicates satisfactory recovery of neuromuscular blockade. The aim of this study was to determine electromyographically the relationship between the TOFRs of the FHBM and the first dorsal interosseous muscle (FDIM), following $0.1 \mathrm{mg} / \mathrm{kg}$ of vecuronium. Eighteen patients were enrolled in this study. Electromyography of the FDIM and the FHBM was monitored. Onset times and recovery times to TOFRs of 0.7 and 0.9 of both muscles after administration of vecuronium were measured. The onset time in the FDIM was not different from that in the FHBM $(P=0.10)$. Recovery time to TOFR 0.7 was significantly faster in the FHBM than in the FDIM $(P<0.013)$. There was no significant difference in the meantime to reach TOFR 0.9 between the FDIM and the FHBM $(P=0.11)$. There is no clinical importance in the difference of neuromuscular recovery between the FHBM and the FDIM after TOFR reached 0.9 following administration of vecuronium.

\section{Introduction}

Neuromuscular blockade is usually monitored in the upper limb muscles, such as the adductor pollicis and the first dorsal interosseous muscles (FDIMs), because these muscles can be easily monitored intraoperatively. In case of difficult accessibility to the upper limbs due to patient position and surgical visibility, the flexor hallucis brevis muscle (FHBM) has been described as an alternative site for intraoperative neuromuscular function monitoring.

Recent studies recommended that the threshold to indicate neuromuscular recovery based on the train-of-four ratio (TOFR) be increased to 0.9 and above, to prevent postoperative respiratory complications $[1,2]$. However, no study has been conducted to investigate the recovery of neuromuscular blockade from non-depolarizing agents in both upper and lower limbs up to the TOFR of 0.9 by using electromyography (EMG). The aim of this study was to investigate the onset and recovery time of the FHBM to TOFR 0.9 following vecuronium administration, and compared with that recorded in the FDIM. Neuromuscular blockade was assessed with EMG in both muscles.

\section{Methods}

Ethical approval for this study (Ethical Committee no. 5-19) was provided by the ethical committee at Fukuoka University, Fukuoka, Japan (Chairperson Prof. T Kawarabayashi) on 26 October 2005. Each patient gave written informed consent prior to study entry. Eighteen $(n=18)$ patients aged between 20 and 70 years with American Society of Anesthesiologists physical status I or II and scheduled for elective ear or eye surgery were included in this study. Patients with apparent neuromuscular disease, renal or liver dysfunction, on medications that could interact with neuromuscular transmission, or with a body mass index over $30 \mathrm{~kg} / \mathrm{m}^{2}$ were excluded. 


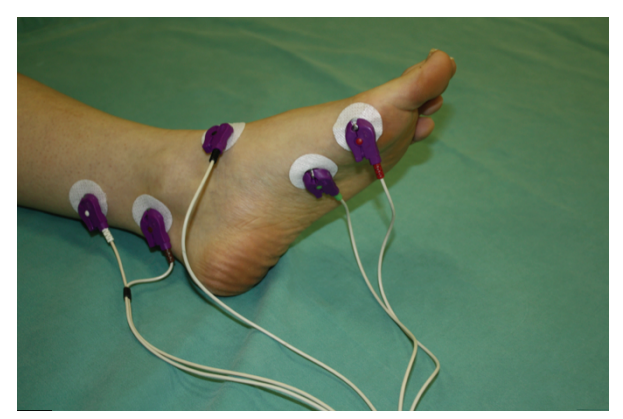

Figure 1: Picture of the electromyography of the flexor hallucis brevis muscle.

All patients were premedicated with diazepam 5-10 mg. After arriving in the operating room, routine monitoring including electrocardiogram, noninvasive blood pressure, and pulse oximetry was commenced. We prepared two anesthesia machines for two EMG monitors (M-NMT, Datex AS/3, Datex-Ohmeda, Finland). The FDIM and the FHBM was each attached to an EMG monitor. Stimulating electrodes were applied to the ulnar nerve proximal to the wrist joint for FDIM, and to the tibial nerve in the inferolateral aspect of the medial malleolus for FHBM (Figure 1). Sensing cutaneous electrodes were applied to the belly and the enthesis of each muscle. The electrodes were applied by two authors (Y. Sugi and K. Nitahara).

Anesthesia was induced with propofol $1.0-2.0 \mathrm{mg} / \mathrm{kg}$. The EMGs were calibrated after the patient lost consciousness. TOF stimuli with an interval of $20 \mathrm{~s}$ were delivered to the ulnar and posterior tibial nerves. The indirectly evoked integrated compound action potentials of the FDIM and the FHBM were measured and recorded as control TOFR and T1/T0 values after $5 \mathrm{~min}$ of response stabilization. A bolus of vecuronium $0.1 \mathrm{mg} / \mathrm{kg}$ was given intravenously, followed by rapid injection of $5 \mathrm{ml}$ of saline. Neuromuscular blockade onset time was defined as time from vecuronium injection to achieving $95 \%$ of T1 block.

Anesthesia was maintained with propofol at $4-10 \mathrm{mg} /$ $\mathrm{kg} / \mathrm{h}$, remifentanil at $0.05-0.3 \mathrm{mg} / \mathrm{kg} / \mathrm{min}$, and intermittent fentanyl $50 \mathrm{mg}$ when required. Ventilation was adjusted to maintain $\mathrm{ETCO}_{2}$ at $30-40 \mathrm{mmHg}$. The temperature of the skin over both muscles was maintained at $32-37^{\circ} \mathrm{C}$ with a heating blanket. Additional vecuronium was not given during surgery. The recovery times of TOFR to 0.7 and 0.9 were then recorded. All data were collected by two authors (Y. Sugi and K. Nitahara). We evaluated spontaneous recovery of neuromuscular blockade in both muscles, until TOFR reached 0.9 .

Data are expressed as mean \pm SD and analyzed using the Student's paired $t$-tests. A $P$ value less than 0.05 was considered statistically significant.

\section{Results}

Twelve men and six women participated in this study. The age was $39 \pm 16$ years, with body height $165 \pm 6 \mathrm{~cm}$ and weight $60 \pm 12 \mathrm{~kg}$.
TABLE 1: Onset and recovery times of the first dorsal interosseous muscle and the flexor hallucis brevis muscle after administration of vecuronium $0.1 \mathrm{mg} / \mathrm{kg}$.

\begin{tabular}{lcc}
\hline & FDIM & FHBM \\
\hline Onset time $(\mathrm{s})$ & $125 \pm 36$ & $142 \pm 37$ \\
Time to TOFR 0.7 $(\mathrm{min})$ & $99.2 \pm 55.8$ & $92.1 \pm 53.9^{*}$ \\
Time to TOFR $0.9(\mathrm{~min})$ & $121.7 \pm 65.6$ & $110.5 \pm 55.6$ \\
\hline
\end{tabular}

Values are mean \pm SD. First dorsal interosseous muscle (FDIM), flexor hallucis brevis muscle (FHBM), and train-of-four ratio (TOFR). The time from Vecuronium $0.1 \mathrm{mg} / \mathrm{kg}$ Injection to Recovery of TOFR 0.7 (time to TOFR 0.7 ), the time from vecuronium $0.1 \mathrm{mg} / \mathrm{kg}$ injection to recovery of TOFR 0.9 (time to TOFR 0.9$)$. $\left({ }^{*} P<0.013\right.$ versus FDIM).

Table 1 shows the onset and recovery times of neuromuscular blockade following administration of vecuronium at $0.1 \mathrm{mg} / \mathrm{kg}$. The onset time in the FDIM was shorter than that in the FHBM by a mean of $17 \mathrm{~s}$. However, the difference was not statistically significant $(P=0.10)$. The mean recovery time to TOFR 0.7 was faster in the FHBM than in the FDIM, by a mean of $7.1 \mathrm{~min}(P<0.013,95 \% \mathrm{CI}$; $1.6-12.5 \mathrm{~min})$. There was no significant difference in the meantime to reach TOFR 0.9 between the FHBM and the FDIM $(P=0.11)$. In all patients, spontaneously recovery of TOFR reached 0.9 and reversal agents were not given during surgery and in the postanesthesia care unit. No patient had respiratory complications and $\mathrm{SpO}_{2}<96 \%$ in postanesthesia care unit.

\section{Discussion}

Mechanomyography at the adductor pollicis muscle is the gold standard in the evaluation of neuromuscular blockade with non-depolarizing neuromuscular relaxants. However, the equipment is bulky, takes time to set up, needs meticulous adjustment, and is not commercially available. The EMG unit is equipped with a Datex AS/3 anesthesia machine. Thus, it is simple to monitor neuromuscular blockade and remains reliable for perioperative use. However, it overestimates recovery of neuromuscular blockade at the adductor pollicis muscle, compared with mechanomyography [3]. The TOFRs of the FIDM assessed by EMG correlate highly with that of the adductor pollicis muscle assessed with mechanomyography at TOF values $>0.7[4,5]$. Therefore, we chose the FDIM instead of the adductor pollicis muscle to evaluate the extent of neuromuscular blockade in the upper limb muscles.

Evaluation of neuromuscular blockade of the upper and lower limb muscles with acceleromyography and EMG showed variable results [6-9]. Our results showed that the time for TOFR to reach 0.7 after vecuronium administration was significantly shorter in the FHMB than in the FDIM. Kern et al. [6] reported that recovery of neuromuscular blockade with mivacurium was shorter in the FHBM than in the adductor pollicis muscle up to TOFR of 0.7 , as assessed by acceleromyography. Sopher et al. [7] also reported that the FHBM recovered faster than the adductor pollicis muscle after vecuronium administration up to $\mathrm{T} 1$ of $25 \%$. Our results are consistent with that reported previously. 
Our results showed that the time for TOFR to recover to 0.9 after vecuronium administration in the FHBM was not different from that recorded in the FDIM. These results indicate that recovery of TOFR up to 0.9 in the FHBM with EMG may be interpreted as clinically safe recovery from neuromuscular blockade.

The onset time to maximum blockade (T0) following intravenous vecuronium $0.1 \mathrm{mg} / \mathrm{kg}$ administration in the FHBM using EMG was $205 \pm 44 \mathrm{sec}$ under fentanyl and droperidol anesthesia, and $153 \pm 23 \mathrm{sec}$ under sevoflurane anesthesia [8]. Our study showed that the onset time in the FHBM was $142 \pm 37 \mathrm{sec}$, which is faster than that reported previously. The main reason for the difference between the outcomes reported previously and our result may be due to the definition of onset time. We defined the onset time as time from vecuronium injection to achieving 95\% blockade. A previous study defined maximum blockade following vecuronium administration as the onset time. Previous studies using acceleromyography showed that the onset time of vecuronium was shorter in the adductor pollicis muscle than in the FHBM $[6,7]$. Our study showed that the mean onset time in the FDIM was $17 \mathrm{~s}$ faster than that in the FHBM although the difference is not statistically significant.

We conclude that since recovery of neuromuscular blockade with vecuronium can be overestimated when neuromuscular blockade is assessed in the flexor hallucis brevis muscle when the TOFR reached 0.7 , administration of an antagonizing agent is recommended. However, there is no clinical importance in the difference of neuromuscular recovery between the FHBM and the FDIM when the TOFR reached 0.9 with EMG following administration of vecuronium.

\section{Conflict of Interests}

The authors declare no conflict of interests.

\section{Acknowledgments}

This clinical trial has been registered at JMA Clinical Trials Registry which participates in the WHO International Clinical Trial Registry Platforms. URL: https://dbcentre3.jmacct .med.or.jp/jmactr/Default_Eng.aspx. Identification number: JMA-IIA00055.

\section{References}

[1] G. S. Murphy, J. W. Szokol, J. H. Marymont, S. B. Greenberg, M. J. Avram, and J. S. Vender, "Residual neuromuscular blockade and critical respiratory events in the postanesthesia care unit," Anesthesia and Analgesia, vol. 107, no. 1, pp. 130-137, 2008.

[2] M. Eikermann, M. Blobner, H. Groeben et al., "Postoperative upper airway obstruction after recovery of the train of four ratio of the adductor pollicis muscle from neuromuscular blockade," Anesthesia and Analgesia, vol. 102, no. 3, pp. 937-942, 2006.

[3] A. F. Kopman, "The relationship of evoked electromyographic and mechanical responses following atracurium in humans," Anesthesiology, vol. 63, no. 2, pp. 208-211, 1985.

[4] J. Engboek, D. Ostergaard, J. Viby-Mogensen, and L. T. Skovgaard, "Clinical recovery and train-of-four ratio meas- ured mechanically and electromyographically following atracurium," Anesthesiology, vol. 71, no. 3, pp. 391-395, 1989.

[5] J. Engbaek, "Monitoring of neuromuscular transmission by electromyography during anaesthesia. A comparison with mechanomyography in cat and man," Danish Medical Bulletin, vol. 43, no. 4, pp. 301-316, 1996.

[6] S. E. Kern, J. A. Orr, O. J. A, and D. R. Westenskow, "Clinical analysis of the flexor hallucis brevis as an alternative site for monitoring neuromuscular block from mivacurium," Journal of Clinical Anesthesia, vol. 9, no. 5, pp. 383-387, 1997.

[7] M. J. Sopher, D. H. Sears, and L. F. Walts, "Neuromuscular function monitoring comparing the flexor hallucis brevis and adductor pollicis muscles," Anesthesiology, vol. 69, no. 1, pp. 129-131, 1988.

[8] T. Kitajima, K. Ishii, T. Kobayashi, and H. Ogata, "Differential effects of vecuronium on the thumb and great toe as measured by accelography and electromyography," Anaesthesia, vol. 50, no. 1, pp. 76-78, 1995.

[9] A. F. Kopman, W. Chin, and J. Cyriac, "Acceleromyography vs. electromyography: an ipsilateral comparison of the indirectly evoked neuromuscular response to train-of-four stimulation," Acta Anaesthesiologica Scandinavica, vol. 49, no. 3, pp. 316-322, 2005. 


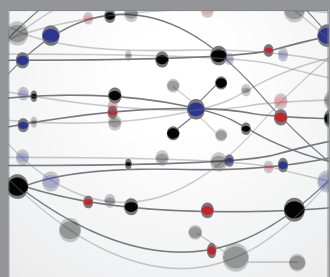

The Scientific World Journal
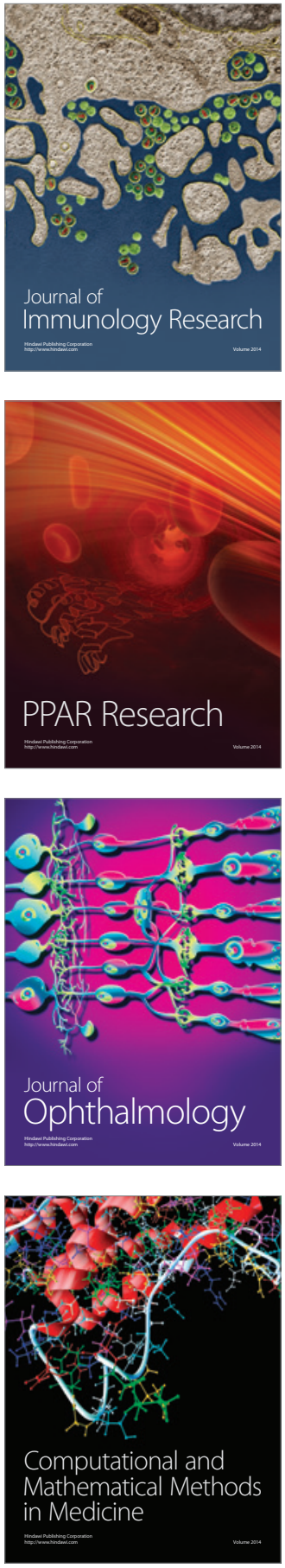

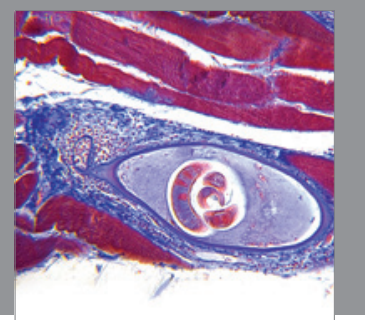

Gastroenterology

Research and Practice
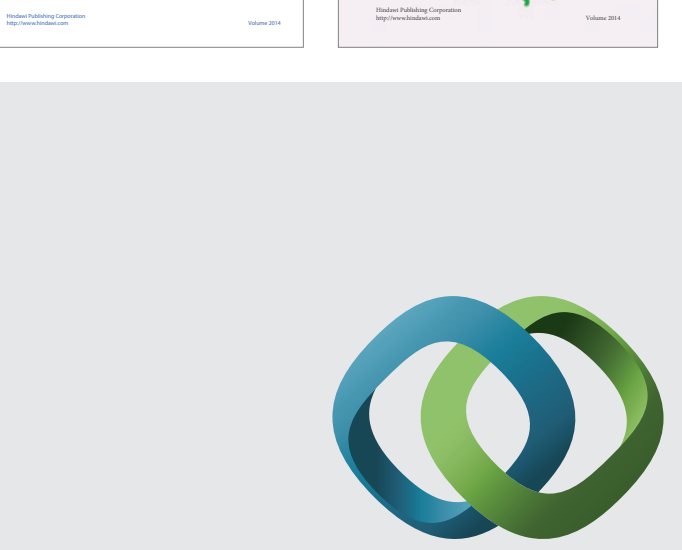

\section{Hindawi}

Submit your manuscripts at

http://www.hindawi.com
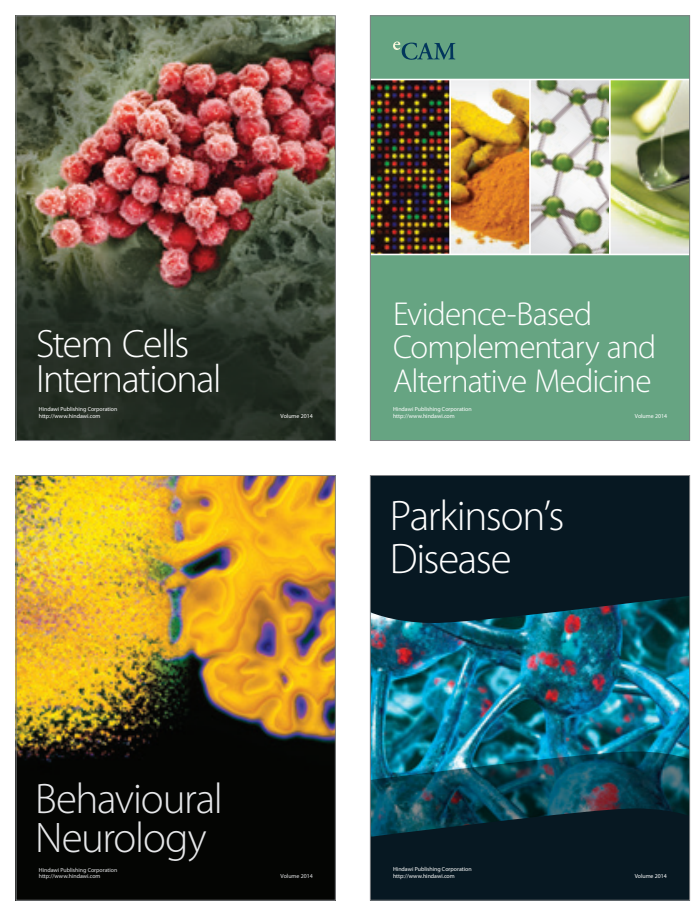

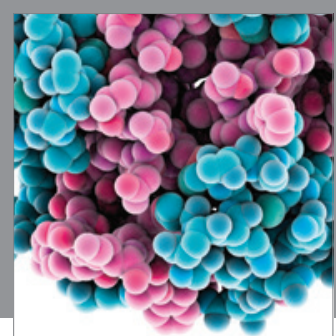

Journal of
Diabetes Research

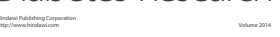

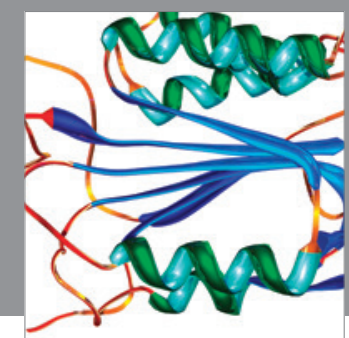

Disease Markers
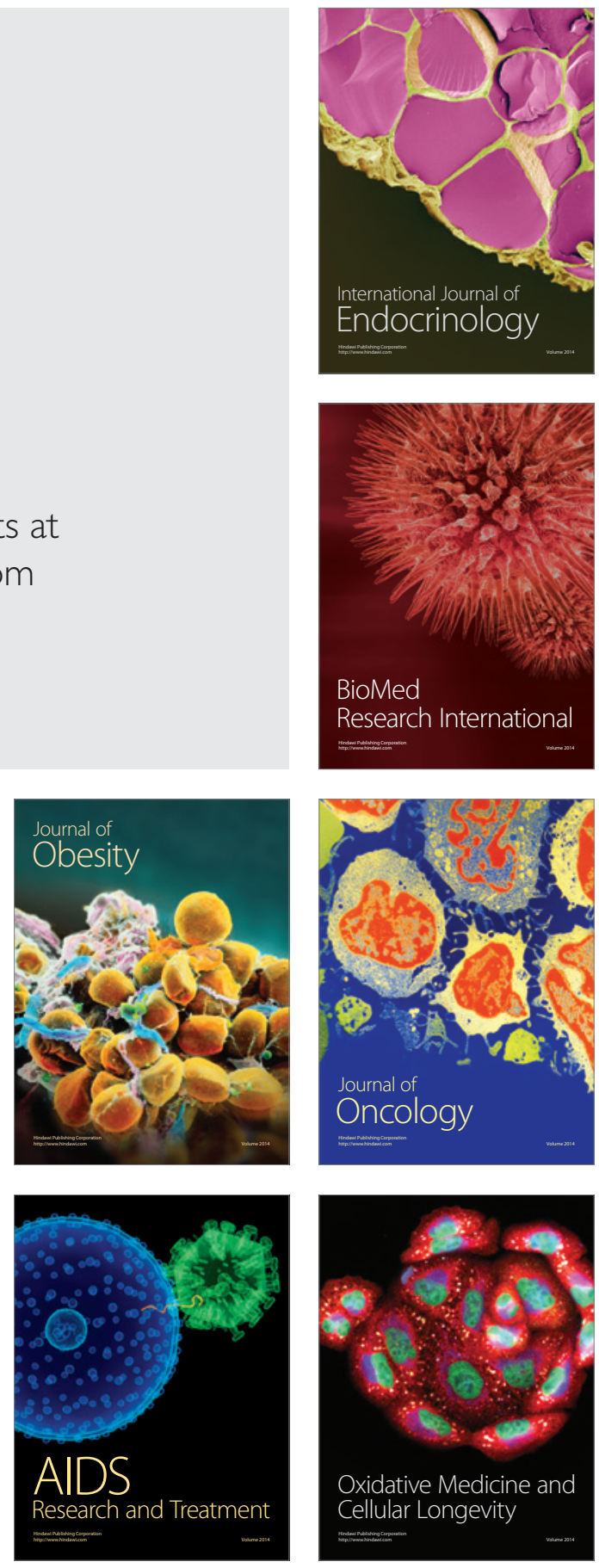